\title{
Nanohybrid sensor based on carboxyl functionalized graphene dispersed palygorskite for voltammertric determination of niclosamide
}

Zhouxiang Zhang ${ }^{1, a, b}$, Yuanyuan Yao ${ }^{1, a, b}$, Jingkun $\mathrm{Xu}^{\mathrm{a}, *}$, Yangping $\mathrm{Wen}^{\mathrm{b}, *}$, Jie Zhang $^{\mathrm{a}, \mathrm{b}}$, and Wanchuan Ding ${ }^{\mathrm{a}, \mathrm{b}}$

${ }^{a}$ School of Pharmacy, Jiangxi Science and Technology Normal University, Nanchang 330013, PR China

${ }^{\mathrm{b}}$ Institute of Functional Materials and Agricultural Applied Chemistry, Jiangxi Agricultural University, Nanchang 330045, P. R. China

*Corresponding author: Fax: +86-791-83823320, Tel.: +86-791-88537967, E-mail: xujingkun@jxstnu.edu.cn (J. Xu) wenyangping1980@gmail.com (Y.Wen)

${ }^{1}$ These authors contributed equally to this work. 


\begin{abstract}
The stably dispersible palygorskite (Pal) nanorods onto carboxyl functionalized graphene $(\mathrm{Gr}-\mathrm{COOH})$ nanosheets were successfully employed for the facile fabrication of a novel nanohybrid sensing platform and the voltammertric determination of niclosamide (NA) in tablet and paddy water samples. A water-processable Gr-COOH can improve the dispersion and stability in water of Pal. The structure and properties of the formed Pal-Gr-COOH nanohybrid were characterized. The electrochemical behavior of NA, analytical conditions and the sensing performance of the prepared sensor were investigated. The sensor displayed the enhanced synergistically electrocatalytic ability toward NA in a linear range from $0.02-0.99 \mu \mathrm{M}$ with low limit of detection (4.6 nM), good sensitivity, high reproducibility and satisfactory practicability, suggesting Pal-Gr-COOH nanohybrid will provide a promising platform for sensing application and facile preparation and potential application of other nanoclay mineral nanocomposites.
\end{abstract}

Keywords Palygorskite, Nanoclay mineral, Carboxyl functionalized graphene, Niclosamide, Nanohybrid 


\section{Introduction}

Niclosamide (2,5-dicloro-4-nitrosalicylanilide, NA), an effective antihelmintic medicine, is widely used in public health, veterinary and aquaculture (Swan, 1999; Datta et al., 2000; Abreu et al., 2002). The World Health Organization has put it as the only commercially available molluscicide for the large-scale use in schistosomisasis control programs (World Health Organization, 1993). However, nowadays, many researchers found it has high toxicity to some aquatic snails and organisms (Andrews et al., 1982; Oliveira-Filho et al., 2000). Thus, it is a great challenge to develop a sensitive and selective method for the NA determination. At present, electrochemical methods have received the increasing attention owning to their many excellent advantages such as rapid, easy operation, high sensitivity, online testing and low-cost. Electrochemical sensor based electroanalytical methods have widely used for various fields such as environmental protection, pharmaceutical monitoring, and so on (Janssen et al., 2002; Karimi-Maleh et al., 2016, 2017). There were also some reports for the NA determination by electroanalytical methods (Sridevi et al., 1991; Alemu et al., 2002, 2003). However, electrochemical sensors based on nanomaterials modified electrodes were mainstream methods of the NA determination in recent years (Ghalkhani et al., 2010; Dede et al., 2014; Yao et al., 2014). Ghalkhani et al fabricated carbon nanoparticle/chitosan nanocomposite modified electrode for detecting NA, and it showed high stability, good reproducibility and excellent electro-catalytic activity toward NA (Ghalkhaniet al., 2010). Mehretie et al also investigated poly 
(3,4-ethylenedioxythiophene) modified glassy carbon electrode (GCE) towards the electrochemical determination of NA with excellent performance (Mehretie et al., 2012). In our previous work, we also built electrochemical sensors based on carbon nanomaterials modified GCE with wonderful properties (Yao et al., 2014). Nevertheless, these nanomaterials were more expensive. Thus, low-cost nanomaterials with excellent properties were necessary to seek for producing novel electrochemical sensors for detecting NA with high effective, cheap and good sensitivity.

Nanoclay minerals are good candidate as modified electrodes for applications in sensors and biosensors due to their exclusive features, such as abundance, high specific surface areas, inexpensive availability, environmental stability, high adsorptive and ion exchange properties (Mousty, 2004; Bergaya et al., 2013). Palygorskite (Pal), a type of hydrated magnesium aluminum silicate rich in the content of natural nanoclay minerals, which has fibrous crystal structure and chemical structural formula $\mathrm{Si}_{8} \mathrm{O}_{20}(\mathrm{Mg}, \mathrm{Al}, \mathrm{Fe})_{5}(\mathrm{OH})_{2}\left(\mathrm{OH}_{2}\right)_{4} \cdot 4 \mathrm{H}_{2} \mathrm{O}$ (Haden et al., 1967; Drits et al., 1971; Gonzalez et al., 1989). Nowadays, Pal has been widely used in foodstuff, environmental protection and medicine owning to its cheap, large specific surface area, strong absorptive capacity and so on, but there were few reports on Pal and its nanocomposites as modified electrodes for applications in sensors and biosensors relatively to other nanoclay minerals like montmorillonite, kaolinite and halloysite (Zen et al., 2004). Therefore, it is well select to fabricate novel sensors for the 
electrochemical determination of analytes based on Pal nanocomposites combined with merits of other nanomaterials.

Graphene (Gr), one of two-dimensional carbon nanomaterials, has given rise to great interest among physical, chemical and material fields since produced in 2004 (Novoselov et al., 2004). Gr possesses ideal geometric construction and unique optic, thermotic, electric and mechanic properties. Thus, potential applications and fundamental research of $\mathrm{Gr}$ have appeared the exponential growth in many fields such as supercapacitors, solar cells, nanometer electrode transistors, electrochemical sensors and composite materials (Stankovich et al., 2006; Geim et al., 2007; Pumera et al., 2010; Brownson et al., 2012; Zhao et al., 2016). In addition, Gr has highly-focused in sensing analysis due to its stable chemical structure, good conductivity, large specific surface area and excellent electrocatalytic properties. However, the stacking interactions between sheet layers and bad solution-processability of Gr limit its ranges of applications. So far, researchers tried to overcome Gr defects mainly through specific functional groups modified on its surface (Si et al., 2008; Ribeiro et al., 2011; Nie et al., 2012). Consequently, carboxyl group functionalized graphene $(\mathrm{Gr}-\mathrm{COOH})$, one of $\mathrm{Gr}$ derivatives with hydrophilic groups, was produced. It not only retained the excellent performance of Gr, but also enhanced its water dispersibility, which also made the excellent performance of Gr-COOH composite materials easy to prepare via strong interaction with other materials. 
In this paper, a low-cost, simple, sensitive, and selective Pal-Gr-COOH modified GCE was fabricated for the voltammetric determination of NA in tablet and paddy water samples. The Pal-Gr-COOH nanohybrid was prepared by introducing Pal into $\mathrm{Gr}-\mathrm{COOH}$ dispersion. The structure and properties of Pal-Gr-COOH were characterized, and the nanohybrid sensor based on Pal-Gr-COOH/GCE was fabricated and applied.

\section{Experimental}

\subsection{Materials and reagents}

Gr-COOH was purchased from Naijing Xianfeng Nanomaterials Technology co., Ltd. Pal and NA was purchased from Sigma-Aldrich. Lithium perchlorate trihydrate $\left(\mathrm{LiClO}_{4} \cdot 3 \mathrm{H}_{2} \mathrm{O}\right)$, D-(+)-Glucose, sodium chloride $(\mathrm{NaCl})$, potassium ferricyanide $\left(\mathrm{K}_{3}\left[\mathrm{Fe}(\mathrm{CN})_{6}\right]\right)$, potassium hexacyanoferrate trihydrate $\left(\mathrm{K}_{4}\left[\mathrm{Fe}(\mathrm{CN})_{6}\right] \cdot 3 \mathrm{H}_{2} \mathrm{O}\right)$, disodium hydrogen phosphate dodecahydrate $\left(\mathrm{Na}_{2} \mathrm{HPO}_{4} \cdot 12 \mathrm{H}_{2} \mathrm{O}\right)$ and sodium dihydrogen phosphate dehydrate $\left(\mathrm{NaH}_{2} \mathrm{PO}_{4} \cdot 2 \mathrm{H}_{2} \mathrm{O}\right)$ were all obtained from the Sinopharm Chemical Reagent Co., Ltd. Nicotinic acid, nickel chloride hexahydrate $\left(\mathrm{NiCl}_{2} \cdot 6 \mathrm{H}_{2} \mathrm{O}\right)$ and potassium nitrate were purchased from Beijing lark technology Co., Ltd. The paddy water was obtained from the rice base of Jiangxi agricultural university, and the pesticide tablets containing NA was purchased from local agro-chemical market. All chemicals were of analytical grade.

\subsection{Apparatus}

Electrochemical experiments were performed using CHI660B electrochemical 
workstation (Shanghai Chenhua Instrument Company, China). The $\mathrm{pH}$ of phosphate buffer solution was measured by a portable $\mathrm{pH}$ meter PHB-5. Scanning electron microscope (SEM) images were obtained using JSM-6700F (JEOL, Japanese). Transmission electron microscope (TEM) images were conducted on TecnaiG220. Fourier transform infrared spectroscopy (FTIR) was recorded on Bruker Vertex 70 FT-IR spectrometer. The X-ray diffraction (XRD) patterns were acquired on X-ray power diffractometer using XRD-6100 (Shimadzu, Japanese).The UV-vis was conducted by Perkin Elmer Lamda 900 UV-vis NIR spectrometer.

\subsection{Fabrication of Pal- Gr-COOH/GCE}

Prior to the modification, the GCE was carefully polished with a leather containing $0.05 \mu \mathrm{m}$ alumina slurry, and then ultrasonically cleaned in deionized water, absolute ethanol and deionized water each for $5 \mathrm{~min}$, respectively. For preparing $1 \mathrm{mg} / \mathrm{ml} \mathrm{Gr}-\mathrm{COOH}$ dispersion, $10 \mathrm{mg}$ Gr-COOH was dissolved in $10 \mathrm{ml}$ deionized water, and ultrasonic two hours. Then, Pal was added into $1 \mathrm{mg} / \mathrm{ml} \mathrm{Gr-COOH}$ dispersion until the concentration of $\mathrm{Pal}$ in $\mathrm{Gr}-\mathrm{COOH}$ dispersion was up to $10 \mathrm{mg} / \mathrm{ml}$, and Pal-Gr-COOH was attained after the homogeneous dispersion. The Pal-Gr-COOH/GCE was fabricated by drop-coating $5 \mu \mathrm{l}$ of Pal-Gr-COOH dispersion on the surface of GCE, and dried in infrared lamp. The preparative procedure of Pal-Gr-COOH/GCE is shown in Scheme 1.

\subsection{Electrochemical measurements}


The electrochemical measurement was carried out in a three-electrode cell with a modified electrode as the working electrode, a Pt wire as the counter electrode and a saturated electrode (SCE) as reference electrode, in $5 \mathrm{ml} 0.1 \mathrm{M}$ phosphate buffered solution at $\mathrm{pH}=7.0$. Before the measurement, electrolyte solutions were purged with nitrogen for $5 \mathrm{~min}$. The electrochemical response was measured by differential pulse anodic stripping voltammetry (DPASV).

\subsection{Samples preparation}

After being centrifuged and filtrated, paddy water was adjusted $\mathrm{pH}$ into 7.0 and stored for following use. For preparing $0.1 \mathrm{mM}$ pesticide sample solution, the tablet was ground into a powder and then dissolved in purified DMF. 


\section{Results and discussion}

\subsection{Characterization of Pal-Gr-COOH}

A white Pal suspension $\left(10 \mathrm{~mL} \mathrm{mg}^{-1}\right)$ (Scheme $\left.2 \mathrm{a}\right)$ with visible large particulates was obtained with the ultrasound for $2 \mathrm{~h}$ in water, and this suspension was prone to aggregate and some white precipitate was observed on the bottom of the bottle. On the contrary, a yellow-brown Gr-COOH (Scheme 2b) homogeneous dispersion (concentration $1 \mathrm{~mL} \mathrm{mg}^{-1}$ ) was prepared by ultrasonic agitation in water for $2 \mathrm{~h}$. More interestingly, the Pal was added into $\mathrm{Gr}-\mathrm{COOH}$ aqueous dispersion, a stable dark-brown Pal-Gr-COOH dispersion (Scheme 2c) was obtained by sufficient ultrasound, and Pal showed an improved dispersion and stability in water, which were mainly ascribed to carboxy groups of Gr nanosheets.

\subsection{1. $U V$-vis}

UV-vis spectroscopy is a useful tool for monitoring any possible change, the strong absorption peak at $230 \mathrm{~nm}$ of $\mathrm{Gr}-\mathrm{COOH}$ in Fig. $1 \mathrm{Ab}$ is attributed to the characteristic absorption of Gr, originating from the $\pi-\pi^{*}$ transitions of aromatic $\mathrm{C}=$ $\mathrm{C}$ bond, and a weak shoulder at $307 \mathrm{~nm}$ attributed to $\mathrm{n}-\pi^{*}$ transitions of $\mathrm{C}=\mathrm{O}$ bonds, corresponding to $\mathrm{n}-\pi^{*}$ transitions of $\mathrm{C}=\mathrm{O}$ bond, which maybe closely related to the degree of reduction of Gr (Deng et al., 2013).The Pal has a weak shoulder at $257 \mathrm{n}$ min Fig. 1Aa, probably because of the mutual interference of polyatomic species $(\mathrm{Mg}$, Al, Fe, Mn, etc (Zhou et al., 2013).When Pal was added into Gr-COOH dispersion, Pal-Gr-COOH appeared a weak shoulder at $246 \mathrm{~nm}$ in Fig. 1Ac, while absorption 
peak of Gr-COOH shifted or disappeared, which were attributed to the interaction between two nanomaterials.

\subsubsection{FTIR}

FTIR spectra of Pal (a), Gr-COOH (b) and Pal-Gr-COOH (c) were presented in Fig. 1B.The presence of peaks at 1026 and $472 \mathrm{~cm}^{-1}$ (Si-O-Si asymmetric stretching vibrations), 3617, 3547 and $3406 \mathrm{~cm}^{-1}$ (different hydroxyl stretching vibration adsorptions) were characteristic spectra of Pal (Fig. 1Ba), which was consistent with the previous report (Li et al., 2010). The peaks at about 1047, 1384, 1624, 1722, 2926 and $3418 \mathrm{~cm}^{-1}$ were feature peaks of $\mathrm{Gr}-\mathrm{COOH}$ (Fig. 1Bb). Stretching vibrations of $\mathrm{COOH}$ and $\mathrm{C}-\mathrm{O}-\mathrm{C}$ in $\mathrm{Gr}-\mathrm{COOH}$ produced peaks at 1722, 3418 and $1047 \mathrm{~cm}^{-1}$, and other peaks at 1384,1624 and $2926 \mathrm{~cm}^{-1}$ were assigned to $\mathrm{OH}$ bending vibration, carbon atoms $\mathrm{sp}^{2}$ hybridization and the vibration of $-\mathrm{CH}_{2}$, respectively(Deng et al., 2011; Bora et al., 2012; Han et al., 2014).As we could see from Fig. 1Bc, peaks location of Pal-Gr-COOH were similar with that of Pal, meanwhile, it also had feature peaks of Gr-COOH. Moreover, peaks of Pal-Gr-COOH hybrids became weak, even disappear, implying Pal interacted with $\mathrm{Gr}-\mathrm{COOH}$.

\subsection{3. $X R D$}

Diffraction reflections at $2 \theta=8.3^{\circ}, 13.8^{\circ}, 19.7^{\circ}$ and $27.7^{\circ}$ (Fig. 1Ca) were corresponding to (110), (200), (040), (400) crystal planes of Pal, respectively, suggesting that Pal had a typical tetrahedral structure (Xu et al., 2009), and the special 
structure was good for the manufacture of sensing devices. After mixed Pal with $\mathrm{Gr}-\mathrm{COOH}$, the nanohybrids had diffraction reflections of both $\mathrm{Pal}$ and $\mathrm{Gr}-\mathrm{COOH}$, indicating that the crystal structure of Pal was not destroyed by Gr-COOH (Fig. $1 \mathrm{Cb}-\mathrm{c})$.

\subsubsection{SEM}

SEM images of Gr-COOH displayed the typical shape of Gr-COOH (Fig. 2A-B), the thin paper-like surface topography had some cracks and crimples, and the high surface roughness of $\mathrm{Gr}-\mathrm{COOH}$ surface was clearly observed. SEM images of $\mathrm{Pal}$ showed short rod-like nanostructure of Pal (Fig. 2C-D), and they stacked together like rice straw. Pal was adhered onto the surface of $\mathrm{Gr}-\mathrm{COOH}$ nanosheets in comparison with Fig. 2C-D. They were got together tightly with each other and formed nanorod network (Fig. 2E-F). Thus, Pal-Gr-COOH nanohybrids had larger surface structure comparing with $\mathrm{Gr}-\mathrm{COOH}$ and $\mathrm{Pal}$, which was beneficial to form larger electroactive area at electrode surface and in favor of the electrochemical determination of analytes.

\subsubsection{TEM}

TEM images of Gr-COOH showed that the $\mathrm{Gr}-\mathrm{COOH}$ was wrinkle-sheet nanostructures, and even a single or double layered $\mathrm{Gr}-\mathrm{COOH}$ was observed (Fig. 3A-B). TEM images of Pal displayed rod-like nanostructures with common diameter, and the diameter was approximately $25 \mathrm{~nm}$ (Fig. 3C-D). When Pal was introduced into $\mathrm{Gr}-\mathrm{COOH}$, Pal nanorods covered onto the surface of $\mathrm{Gr}-\mathrm{COOH}$ nanosheets, and 
its intensive degree and diameter have increased (Fig. 3E-F). According to above surface features, it demonstrated that Pal-Gr-COOH was well mingled together, and Gr-COOH has no effect on the crystal form of Pal. In addition, SEM results were in accordance with that of TEM, they also revealed the reason of the improved dispersion and stability in water of Pal.

\subsubsection{EIS}

Nyquist plots of GCE, Pal/GCE, Gr-COOH/GCE and Pal-Gr-COOH/GCE (Fig. 4a-d) were measured in the presence of $5 \mathrm{mM}\left[\mathrm{Fe}(\mathrm{CN})_{6}\right]^{3-/ 4-}$ containing $0.1 \mathrm{M} \mathrm{KCl}$. The EIS of the bare GCE displayed a small semicircle at high frequencies (Fig. 4a), indicating that the charge transfer resistance at GCE was very low. After modifying with Pal, a large semicircle was emerged (Fig. 4b) due to its non-conductivity. Subsequently, when the GCE was modified with Gr-COOH, the size of the semicircle of $\mathrm{Gr}-\mathrm{COOH} / \mathrm{GCE}$ was larger than that of Pal/GCE (Fig. 4c), which was mainly ascribed to the electrostatic repulsion between negatively charged functional group of Gr and negative charge of the redox probe $\left[\mathrm{Fe}(\mathrm{CN})_{6}\right]^{3-/ 4-}$ (Devi et al., 2015; Punckt et al., 2016). Finally, after Pal-Gr-COOH nanohybrid was drop-coated onto the GCE (Fig. 4d), the size of the semicircle of Pal-Gr-COOH was between that of both Gr-COOH/GCE and Pal/GCE, this is most likely to be related to the introduction of negative charges of Gr-COOH and bad conductivity of Pal, and also implying Pal and Gr-COOH has been mixed absolutely from another aspect.

To further explore the electrochemical performance of different modified 
electrodes, CVs of GCE (a), Pal/GCE (b), Gr-COOH/GCE (c) and Pal-Gr-COOH/GCE (d) were carried out in $5 \mathrm{mM}\left[\mathrm{Fe}(\mathrm{CN})_{6}\right]^{3-/ 4-}$ containing $0.1 \mathrm{M} \mathrm{KCl}$. All modified electrodes demonstrated a pair of reduction-oxidation peaks, but all peak currents were smaller than that of the GCE (Fig. 4 inset), Moreover, peak currents of Gr-COOH/GCE, Pal/GCE, and Pal-Gr-COOH/GCE were increasing in turn, which were attributed to their high electron transfer resistance. These results of CVs were in accordance with that of EIS. In addition, the peak current of Gr-COOH/GCE was smaller than bare GCE, this was completely different from Gr-COOH/GCE, (In general, the peak current of Gr-COOH/GCE was higher than bare GCE), the decreased current also revealed that increase in the negative charges at the electrode surface and enhances electrostatic repulsion between the $\mathrm{Gr}-\mathrm{COOH}$ and the redox probe (Devi et al., 2015; Punckt et al., 2016).

\subsection{Electrochemical behaviors of $N A$}

CVs of $50 \mu \mathrm{M}$ NA at GCE (a), Pal/GCE (b), Gr-COOH/GCE (c) and Pal-Gr-COOH/GCE (d) in 0.1 M phosphate buffered solution ( $\mathrm{pH}$ 7.0) were presented in Fig. 5A. All modified electrodes exhibited an irreversible reduction peak and a pair of redox peaks, which was consistent with previous reports (Yao et al., 2014). The peak current of Pal/GCE was higher than that of bare GCE, which might be assigned to its large specific area and good electrocatalytic activity (Fig. 5Aa). Nevertheless, the peak current of Gr-COOH/GCE was enhanced after GCE was modified with $\mathrm{Gr}-\mathrm{COOH}$, Interestingly, the peak current of Gr-COOH/GCE was larger than that of 
Pal/GCE and GCE (Fig. 5Ac), which was obviously different from Fig. 4 inset. The main reason is that Gr-COOH showed excellent electrocatalytic ability for the redox of NA, and the analyte NA is no charge. In addition, quantum chemical calculations in our studies revealed that carboxyl group of function materials could easily interact with in analytes containing amide via the hydrogen bond (Zhang et al., 2013; Yao et al., 2014). Besides, the peak current of Pal-Gr-COOH/GCE was largest than that of three modified electrodes, which might be the synergistic effect between Pal and Gr-COOH (Fig. 5Ad).

To more clearly demonstrate the difference of the electrochemical behaviors of NA at different modified electrodes, DPASV of NA at GCE (a), Pal/GCE (b), Gr-COOH/GCE (c) and Pal-Gr-COOH/GCE (d) were performed in $0.1 \mathrm{M}$ phosphate buffered solution ( $\mathrm{pH} 7.0$ ) containing $20 \mu \mathrm{M}$ NA. It could be seen from Fig. 5B that the electrochemical behaviors of NA at all modified electrodes by DPASV were more obviously. The GCE has a weak oxidation peak at around $-0.13 \mathrm{~V}$ (Fig. 5Ba). The oxidation peak of NA was enlarged when the GCE was modified with Pal (Fig. 5Bb). Subsequently, the height of the oxidation peak at Gr-COOH/GCE was about two times higher than that of $\mathrm{Pal} / \mathrm{GCE}$ (Fig. 5Bc). In comparison with other three modified electrodes, the Pal-Gr-COOH/GCE exhibited the highest peak height and the sharpest peak shape (Fig. 5Bd). All the above results were consistent with CVs of all modified electrode.

\subsection{Optimization of experimental conditions}




\subsubsection{Effect of mass ratios both $\mathrm{Gr}-\mathrm{COOH}$ and Pal}

The different mass ratio between $\mathrm{Gr}-\mathrm{COOH}$ and $\mathrm{Pal}$ on the electrode surface has an effect on the DPASV current response toward NA. Here, the Pal-Gr-COOH composite with different mass ratio was investigated in $0.1 \mathrm{M}$ phosphate buffered solution ( $\mathrm{pH} 7.0$ ) containing $20 \mu \mathrm{M}$ NA. It could be seen in Fig. 6 that the current response of NA at Pal-Gr-COOH/GCE decreased with the increase of the ratio of Gr-COOH towards Pal from 0.1 to 0.9 , which was closely related to Pal content with large specific area onto $\mathrm{Gr}-\mathrm{COOH}$ sheet and the water dispersibility of $\mathrm{Gr}-\mathrm{COOH}$ sheet (A large amount of Gr-COOH easily agglomerated and precipitated). Therefore, the optimum ratio of $\mathrm{Pal}-\mathrm{Gr}-\mathrm{COOH}$ was chosen as 0.1 .

\subsubsection{Effect of buffer solutions}

The concentration of all buffer solutions was $0.1 \mathrm{M}$. and $\mathrm{pH}$ value was adjusted to 7.0 by $\mathrm{NaOH}$ and $\mathrm{HCl}$. NA presented a low peak height and ugly peak shape in $\mathrm{CH}_{3} \mathrm{COONa}, \mathrm{LiClO}_{4}$ and $\mathrm{KCl}$ buffer solutions (Fig. 7). On the contrary, a pretty good oxidation peak was appeared in $\mathrm{NH}_{4} \mathrm{Cl}$ and Britton-Robinson (B-R) buffer solutions. But there was a better peak shape and higher height in phosphate buffered solution. Hence, phosphate buffered solution was chosen as buffer solution in subsequent experiments.

\subsubsection{Effect of scan rates}

Obviously, a pair of reversible redox peak with well peak shape and a poor reduction peak were observed from $\mathrm{CV}_{\mathrm{s}}$ with scan rates from 20 to $500 \mathrm{mV} \mathrm{s}^{-1}$ (Fig. 
8), which was related to the electrochemical reaction mechanism of NA (Yao et al., 2014). Moreover, the logarithm of oxidation peak currents $\left(\log I_{\mathrm{pa}}\right)$ and reduction peak currents $\left(\log I_{\mathrm{pa}}\right)$ show a better linear relationship with the logarithm of scan rates (log $v)$, and the regression equation was $\log I_{\mathrm{pa}}(\mu \mathrm{A})=0.788 \log v-0.831\left(\mathrm{R}^{2}=0.9968\right)$ and $\log I_{\mathrm{pc}}(\mu \mathrm{A})=0.745 \log v-0.886\left(\mathrm{R}^{2}=0.9936\right)\left(v\right.$ in $\mathrm{mV} \mathrm{s}^{-1}$, Fig. 8 inset $)$, we could infer that the reaction of Pal-Gr-COOH/GCE was controlled by adsorption process according to slopes of two linear equations range from 0.5 to 1 (Uslu et al., 2008)

\subsubsection{Effect of $p H$}

NA is usually unstable in strong acid medium (Mehretie et al., 2012), while it is easily hydrolyzed in strong alkaline media (Al- Hadiya et al., 2005), thus the effect of $\mathrm{pH}$ values on the NA determination at $\mathrm{Pal}-\mathrm{Gr}-\mathrm{COOH} / \mathrm{GCE}$ over the range of $\mathrm{pH} 4.0-$ 8.0 was explored by DPASV. The peak currents of NA at Pal-Gr-COOH/GCE increased gradually with the increasing $\mathrm{pH}$ value until it reached the maximum at $\mathrm{pH}$ 7.0, but it decreased rapidly when $\mathrm{pH}$ increased further (Fig. 9). Therefore, phosphate buffered solution with $\mathrm{pH} 7.0$ was chosen for following study. In addition, $E_{\mathrm{p}}$ decreased with the increase of $\mathrm{pH}$ values, ant the linear relationship is $E_{\mathrm{p}}(\mathrm{V})=$ $0.0468 \mathrm{pH}+0.190\left(\mathrm{R}_{2}=0.9988\right)$, and the slope is $46 \mathrm{mV} \mathrm{pH}^{-1}$, which was close to the theoretical value of $58.5 \mathrm{mV} \mathrm{pH}^{-1}$. According to the Nernst equation, we could speculate that the numbers of electrons and protons were equivalent, implying that the electrochemical redox of NA was a two-electron and two-proton process in 
combination with our previous reports (Yao et al., 2014).

\subsection{Determination of NA}

DPASV method was used to determine NA at different concentrations in $0.1 \mathrm{M}$ phosphate buffered solution ( $\mathrm{pH}$ 7.0). Peak currents at Pal-Gr-COOH/GCE were proportional to NA concentrations (Fig. 10). The modified electrode showed a great linear range from $0.02-0.99 \mu \mathrm{M}$, a limit of detection is $4.6 \mathrm{nM}$, and a linear equation was $I(\mu \mathrm{A})=0.736+0.68 \mathrm{C}(\mu \mathrm{M})\left(\mathrm{R}^{2}=0.9986\right)($ Fig. 10 inset $\mathrm{B})$. In comparison with previous reports (Alemu et al., 2002 and 2003; Ghalkhani et al., 2010; Mehretie et al., 2012; Yao et al., 2014; Wang et al., 2014; Dede et al., 2014), the prepared sensor has higher sensitivity and lower limit of detection (Table 1), which mainly ascribe to the large surface area and strong adsorption of both Pal and $\mathrm{Gr}-\mathrm{COOH}$, including high surface catalytic activity of Gr-COOH.

Under the same conditions, five modified electrodes were used to determine NA, respectively, and the relative standard deviation was $2.5 \%$. Besides, every modified electrode was carried out thirty consecutive measurements, and the relative standard deviation was $1.9 \%$. Thus, the modified electrode possessed good repeatability.

\subsection{Interference}

The anti-interference ability of Pal-Gr-COOH/GCE was investigated in $0.1 \mathrm{M}$ phosphate buffered solution ( $\mathrm{pH}$ 7.0) containing $50 \mu \mathrm{M}$ NA in the presence of some substances such as the same concentration for glucose, nicotinic acid, $\mathrm{Na}^{+}, \mathrm{Ni}^{2+}, \mathrm{K}^{+}$. 
As shown in Fig. 11, there are no obvious changes in the current responses for NA in the presence of different interferences due to the weak electrochemical activity or relatively far away from oxidation potentials, which did not cause significantly interference.

\subsection{Samples analysis}

To evaluate the feasibility and precision of Pal-Gr-COOH/GCE, the NA tablet and paddy water were conducted the practical sample analysis by standard addition method. Table 2 indicated that recoveries of NA tablet and paddy water samples were $96.0 \%-102.5 \%$ and $96.2 \%-102.0 \%$, respectively, suggesting that electrochemical detection of NA using the fabricated composite modified electrode is feasible. The content of NA in a tablet was $490.2 \mathrm{mg}$, but the real content in a NA tablet sample was $500 \mathrm{mg}$, so the error between them was $1.96 \%$. Moreover, each sample solution was submitted to three parallel detections, and the RSD for the different concentration levels was no more than $4.35 \%$, suggesting that results obtained by the modified electrode were acceptable. To further confirm the accuracy of this electrochemical detection method in practical application, the same contents of NA were also detected using HPLC. The results obtained by HPLC and with the fabricated electrochemical sensor based on Pal-Gr-COOH/GCE were in good agreement, suggesting that the newly developed method is accurate and has promise for application. Thus, the modified electrode was an excellent sensing platform for the NA analysis of practical samples. 


\section{Conclusions}

A novel nanohybrid film with advantages of the excellent performance of both Pal and Gr-COOH was successfully used to fabricate a cheap, simple, and sensitive sensor for electrochemically detecting NA. The nanohybrid was prepared by adding Pal into $\mathrm{Gr}-\mathrm{COOH}$ dispersion. The structure and properties of $\mathrm{Pal}-\mathrm{Gr}-\mathrm{COOH}$ nanohybrid film were investigated by UV-vis, FT-IR, XRD, SEM and TEM. The Pal-Gr-COOH/GCE exhibited a linear detection range from $0.02-0.99 \mu \mathrm{M}$ with low limit of detection (4.6 nM) under optimal conditions. The prepared sensor has high reproducibility and good sensing stability for NA determination. Moreover, the modified electrode was successfully applied to analyze the trace NA in real samples (NA tablets and paddy water) with satisfactory results. The work will provide a stably dispersible Pal nanohybrid with Gr-COOH for application in sensing NA, and enlarge the potential application in different fields of other nanoclay mineral nanocomposites with hydrophilic nanometer materials.

\section{Conflict of interest}

The authors declare that they have no conflict of interest.

\section{Acknowledge}

The work was supported by the National Science Foundation of China (51572117, 51463008, and 51662014), Natural Science Foundation of Jiangxi Province (20142BAB216032) and Jiangxi Science and Technology Normal University Program for Scientific Research Innovation Team (2015CXTD001). 


\section{References}

Abreu, F.C., Goulart, M.O.F., Brett, A.M.O., 2002. Detection of the damage caused to DNA by niclosamide using an electrochemical DNA-biosensor. Biosens. Bioelectron. 17(11), 913-919.

Alemu, H., Wagana, P., Tseki, P.F., 2002. Voltammetric determination of niclosamide at a glassy carbon electrode. Analyst127(1), 129-134.

Alemu, H., Khoabane, N.M., Tseki, P.F., 2003. Electrochemical oxidation of the niclosamide at a glassy carbon electrode and its determination of voltammetry. Bull Chem. Soc. Ethiopia. 17(1), 95-106.

Al-Hadiya, B.M.H., 2005. Niclosamide: comprehensive profile. Profile. Drug Subst. Excipient. Relat. Methodol. 32, 67-96.

Andrews, P., Thyssen, J., Lorke,D., 1982. The biology and toxicology of molluscicides. Pharmacol. Therapeut. 19(2), 245-295.

Bergaya, F., Lagaly, G., 2013. Handbook of clay science. Newnes.

Bora, C., Dolui, S.K., 2012. Fabrication of polypyrrole/graphene oxide nanocomposites by liquid/liquid interfacial polymerization and evaluation of their optical, electrical and electrochemical properties. Polymer 53(4), 923-932.

Brownson, D.A.C., Kampouris, D.K., Banks, C.E., 2012. Graphene electrochemistry: fundamental concepts through to prominent applications. Chem. Soc. Rev. 41, 6944-6976.

Datta, G., Bera, T., 2000. The effects of clofazimine, niclosamide \& amphotericin B, on electron transport of Leishmania donovani promastigotes. Indian J. Med. Res. 112:15.

Dede, E., Sağlam, Ö., Dilgin, Y., 2014. Sensitive voltammetric determination of niclosamide at a disposable pencil graphite electrode. Electrochim. Acta. 127, 20-26.

Deng, D., Jiang, X., Yang, L., Hou, X., Zheng, C., 2013. Organic solvent-free cloud point extraction-like methodology using aggregation of graphene oxide. Anal. Chem. 86(1), 758-765.

Deng, M., Yang, X., Silke, M., Qiu, W.M., Xu, M.S., Borghs, G., Chen, H.Z., 2011. Electrochemical deposition of polypyrrole/graphene oxide composite on microelectrodes towards tuning the electrochemical properties of neural probes. Sensor. Actuat. B-Chem. 158(1), 176-184.

Devi, M.M., Sahu, S.R., Mukherjee, P., Sen, P., Biswas, K., 2015. Graphene: a self-reducing template for synthesis of graphene-nanoparticles hybrids. RSC. Adv. 5, 62284-62289.

Drits, V.A., Sokolova, G.V., 1971. Structure of palygorskite. Am. Inst. Phys.

Geim, A.K., Novoselov, K.S., 2007. The rise of graphene. Natmater. 6(3), 183-191.

Ghalkhani, M., Shahrokhian, S., 2010. Application of carbon nanoparticle/chitosan modified electrode for the square-wave adsorptive anodic striping voltammetric determination of niclosamide. Electrochem. Commun.12, 66-69. 
Gonzalez, F., Pesquera, C., Blanco, C., Benito, I., Mendioroz, S., Pajares, J.A., 1989. Structural and textural evolution of Al-and Mg-rich palygorskites, I. Under acid treatment. Appl. Clay Sci. 4(4), 373-388.

Haden, W.L., Schwint, I.A., 1967. Attapulgite: its properties and applications. Ind. Eng. Chem. 59(9), 58-69.

Han, H.S., Lee, H.K., You, J.M., Jeong, H., Jeon, S., 2014. Electrochemical biosensor for simultaneous determination of dopamine and serotonin based on electrochemically reduced GO-porphyrin. Sensor. Actuat. B-Chem.190, 886-895.

Janssen, L.J.J., Koene, L., 2002. The role of electrochemistry and electrochemical technology in environmental protection. Chem. Eng. J. 85(2), 137-146.

Karimi-Maleh, H., Shojaei, A.F., Tabatabaeian, K., Karimi, F., Shakeri, S., Moradi, R., 2016. Simultaneous determination of 6-mercaptopruine, 6-thioguanine and dasatinib as three important anticancer drugs using nanostructure voltammetric sensor employing Pt/MWCNTs and 1-butyl-3-methylimidazolium hexafluoro phosphate. Biosens. Bioelectron. 86, 879-884.

Karimi-Maleh, H., Ganjali, M.R., Norouzi, P., Bananezhad, A., 2017. Amplified nanostructure electrochemical sensor for simultaneous determination of captopril, acetaminophen, tyrosine and hydrochlorothiazide. Mat. Sci. Eng. 73, 472-477.

Li, Z.H., Zhang, L., Zang, Z.P., Chang, X.J., Zou, X.J., 2010. Attapulgite modified with 2-hydroxy-1-naphthaldehyde as selective solid-phase extractant for determination of copper(II) in environmental samples by ICP-OES. Microchim. Acta. 171, 161-168.

Mehretie, S., Admassie, S.,Tessema, M., Solomon, T., 2012. Electrochemical study of niclosamide at poly(3,4-ethylenedioxythiophene) modified glassy carbon electrode. Sensor. Actuat. B-Chem. 168, 97-102.

Mousty, C., 2004. Sensors and biosensors based on clay-modified electrodes-new trends. Appl. Clay. Sci. 27(3), 159-177.

Nie, G.M., Bai, Z.M., Chen, J., Yu, W.Y., 2012. Simple label-free femtomolar DNA detection based on a nanostructure composite material: MWNT-doped poly (indole-6-carboxylic acid). ACS. Macro. Letters. 1(11), 1304-1307.

Novoselov, K.S., Geim, A.K., Morozov, S.V., Jiang, D., Zhang, Y., Dubonos, S.V., Grigorieva, I.V., Firsov, A.A., 2004. Electric field effect in atomically thin carbon films. Science. 306(5696), 666-669.

Oliveira-Filho, E.C., Paumgartten, F.J.R., 2000. Toxicity of euphorbia milii latex and niclosamide to snails and nontarget aquatic species. Ecotox. Environ. Safe. 46(3), 342-350.

Pumera, M., Ambrosi, A., Bonanni, A., Chng, E.L.K., Poh, H.L., 2010. Graphene for electrochemical sensing and biosensing. Trend Anal. Chem. 29(9), 954-965.

Punckt, C., Pope, M., A., Liu, Y.M., Aksay, I.A., 2016. Structure-Dependent Electrochemistry of Reduced Graphene Oxide Monolayers. J. Electrochem. Soc. 163, H491-H498.

Ramesha, G.K., Sampath, S., 2009. Electrochemical reduction of oriented graphene 
oxide films: an in situ raman spectroelectrochemical study. J. Phys. Chem. C. 113(19), 7985-7989.

Ribeiro, W.F., Selva, T.M.G., Lopes, I.C., Coelho, E.C.S., Lemos, S.G., Abreu, F.C., Nascimento, V.B., Araujo, M.C.U., 2011. Electroanalytical determination of carbendazim by square wave adsorptive stripping voltammetry with a multiwalled carbon nanotubes modified electrode. Anal. Methods 3, 1202-1206.

Si, Y.C., Samulski, E.T., 2008. Synthesis of water soluble grapheme. Nano. Lett. 8(6), 1679-1682.

Sridevi, C., Reddy, S.J., 1991. Voltammetric determination of niclosamide. J. Indian. Chem. Soc. 68(5), 263-266

Stankovich, S., Dikin, D.A., Dommett, G.H.B., Kohlhaas, K.M., Zimney, E.J., Stach, E.A., Piner, R.D., Nguyen, S.T., Ruoff, R.S., 2006. Graphene-based composite materials. Nature 442(7100), 282-286.

Swan, G.E., 1999. The pharmacology of halogenated salicylanilides and their anthelmintic use in animals: review article. J. S. Afr. Vet. Assoc. 70(2), 61-70.

Uslu, B., Topal, B.D., Ozkan, S.A., 2008. Electroanalytical investigation and determination of pefloxacin in pharmaceuticals and serum at boron-doped diamond and glassy carbon electrodes. Talanta 74, 1191-1200.

Wang, Z., Xu, J., Yao, Y., Zhang, L., Wen, Y., Song, H., Zhu, D., 2014. Facile preparation of highly water-stable and flexible PEDOT: PSS organic/inorganic composite materials and their application in electrochemical sensors. Sensor. Actuat. B-Chem. 196, 357-369.

World Health Organization. 1993. The control of schistosomiasis: second report of the WHO Expert Committee [meeting held in Geneva from 8-15 November 1991].

Xu, J.M., Han, W.X., Yin, Q.F., Song, J., Zhong, H., 2009. Direct electron transfer of glucose oxidase and glucose biosensor based on nano-structural attapulgite clay matrix. Chin. J. Chem. 27, 2197-2202.

Yao, Y.Y., Zhang, L., Duan, X.M., Xu, J.K., Zhou, W.Q., Wen, Y.P., 2014. Differential pulse striping voltammetric determination of molluscicide niclosamide using three different carbon nanomaterials modified electrodes. Electrochim. Acta. 127, 86-94.

Yao, Y.Y., Wen, Y.P., Zhang, L., Wang, Z.F., Zhang, H., Xu, J.K., 2014. Electrochemical recognition and trace-level detection of bactericide carbendazim using carboxylic group functionalized poly (3, 4-ethylenedioxythiophene) mimic electrode. Anal. Chim. Acta. 831, 38-49.

Zen, J.M., Kumar, A.S., 2004. Peer reviewed: the prospects of clay mineral electrodes. Anal. Chem. 76(11), 205 A-211 A.

Zhang, G., Wen, Y.P., Li, Y.Z., Xu, J.K., Guo, C.Q., Lu, B.Y., Zhu, D.H., 2013. Efficient fluorescent recognition of carboxylates in aqueous media using facilely electrosynthesized poly (9-aminofluorene). J. Fluoresce. 23(5), 1053-1063.

Zhao, D., Wang, Y., Nie, G.M., 2016. Electrochemical immunosensor for the carcinoembryonic antigen based on a nanocomposite consisting of reduced graphene oxide, gold nanoparticles and poly (indole-6-carboxylic acid). 
Microchim. Acta. 183(11), 2925-2932.

Zhou, X., Liu, Y., Meng, X., Shen, B., Xiao, F., 2013. Synthesis and catalytic cracking performance of Fe/Ti-ZSM-5 zeolite from attapulgite mineral. Chinese J. Catal. 34(8), 1504-1512. 

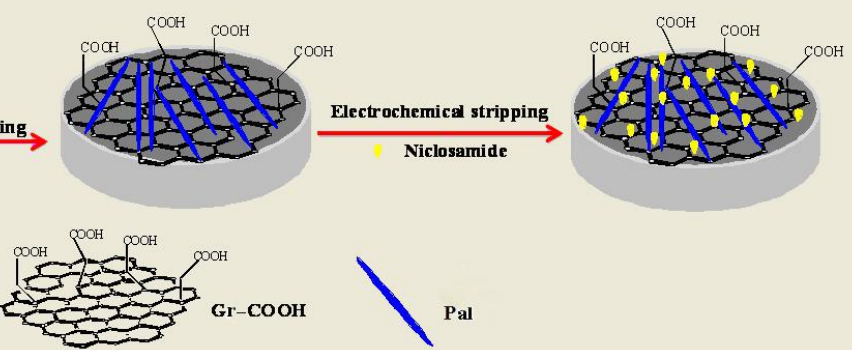

Scheme 1. The preparation process of Pal-Gr-COOH/GCE. 


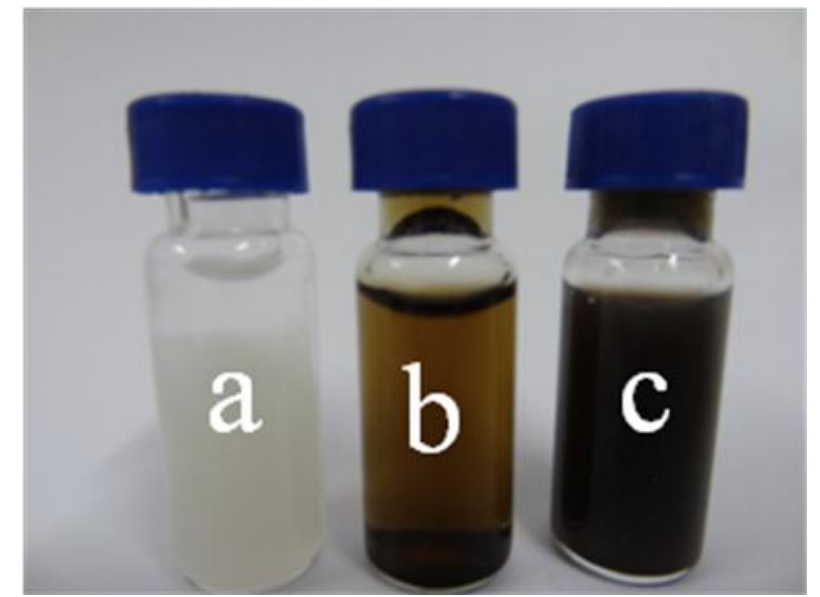

Scheme 2. The preparation of Pal (a), Gr- $\mathrm{COOH}(\mathrm{b})$ and Pal-Gr-COOH (c). 

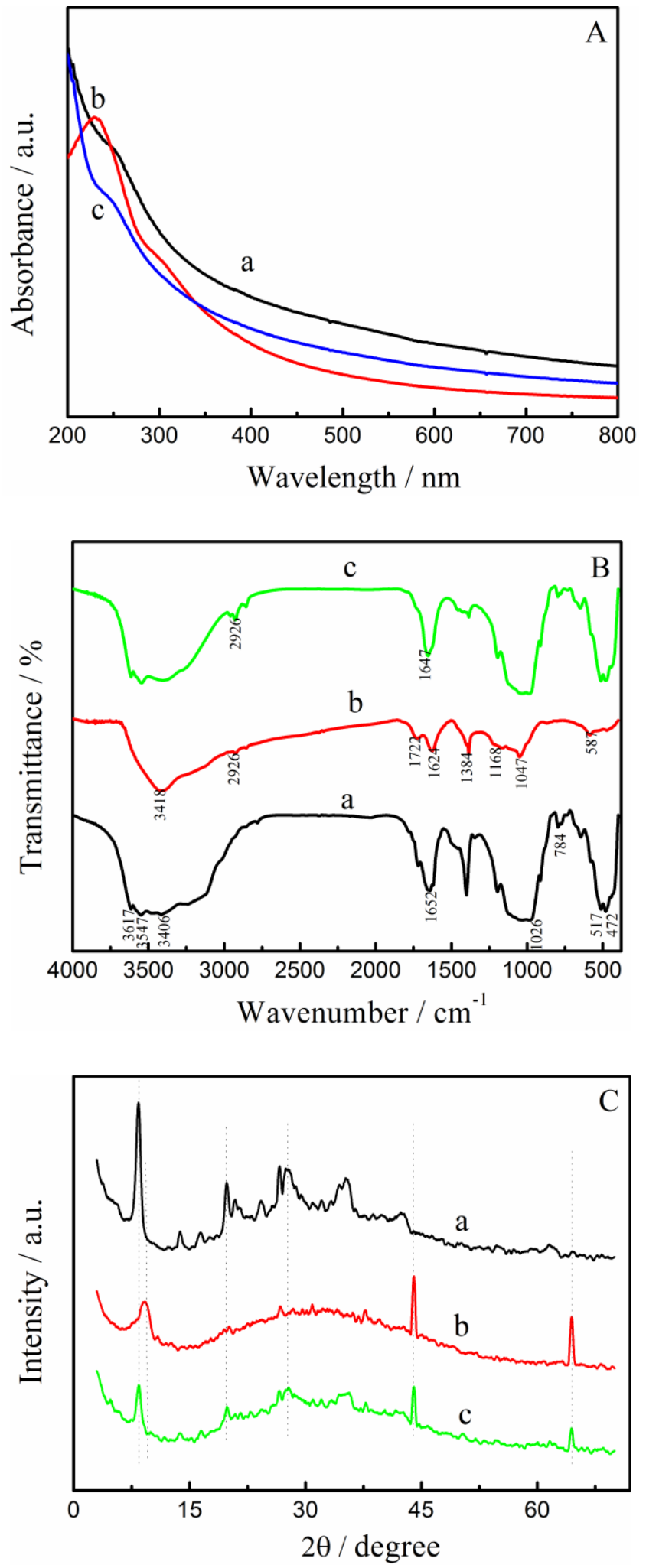

Figure. 1. UV-vis spectra (A), FT-IR spectra (B), XRD patterns (C) of modified electrodes materials Pal (a), Gr- $\mathrm{COOH}$ (b) and Pal-Gr-COOH (c). 


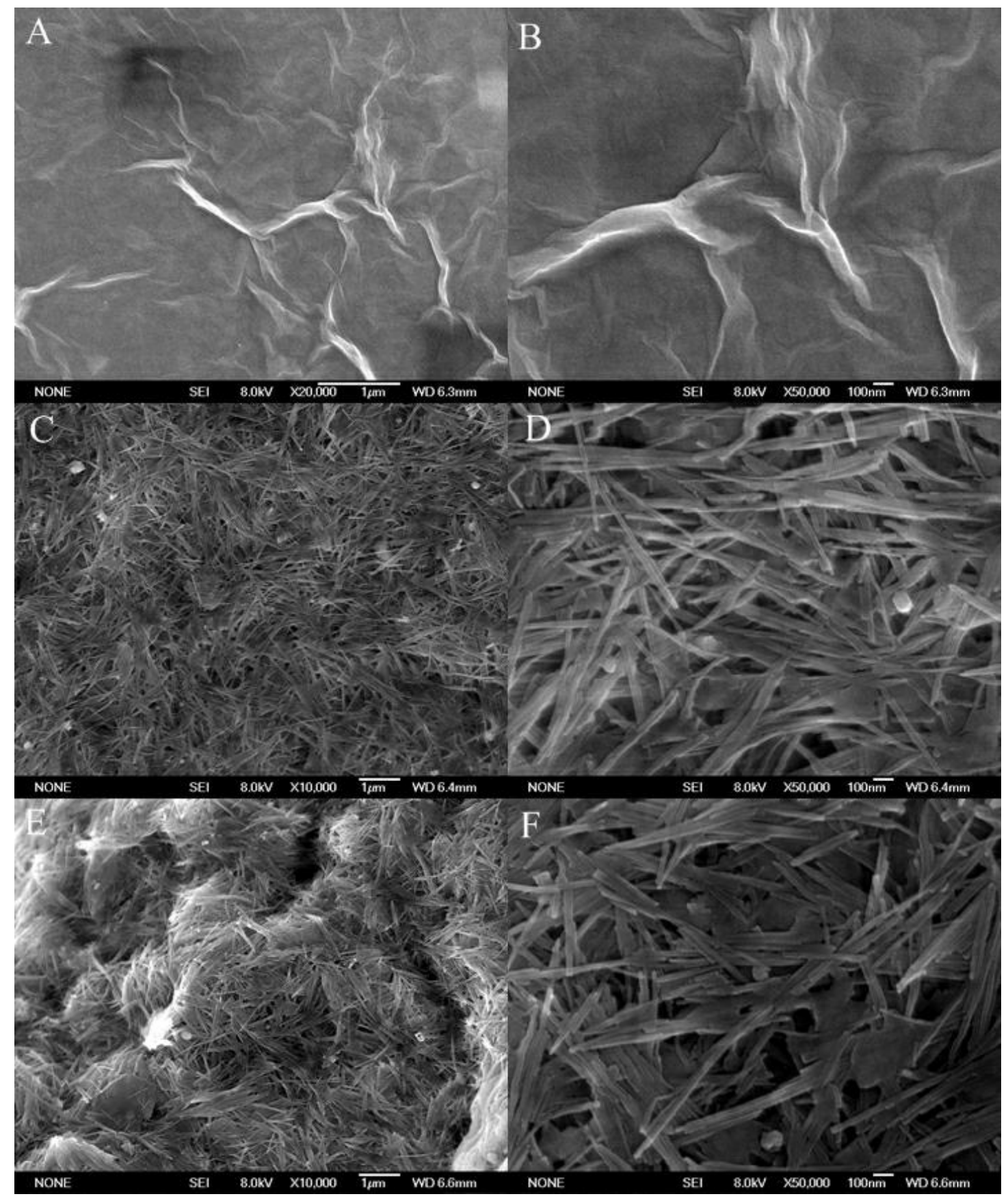

Figure. 2. SEM images of Gr-COOH/GCE $(A \times 20000 ; B \times 50000), P a l / G C E(C \times 10000$;
$\mathrm{D} \times 50000)$
and
Pal-Gr-COOH/GCE
(Ex10000;
$\mathrm{F} \times 50000)$. 


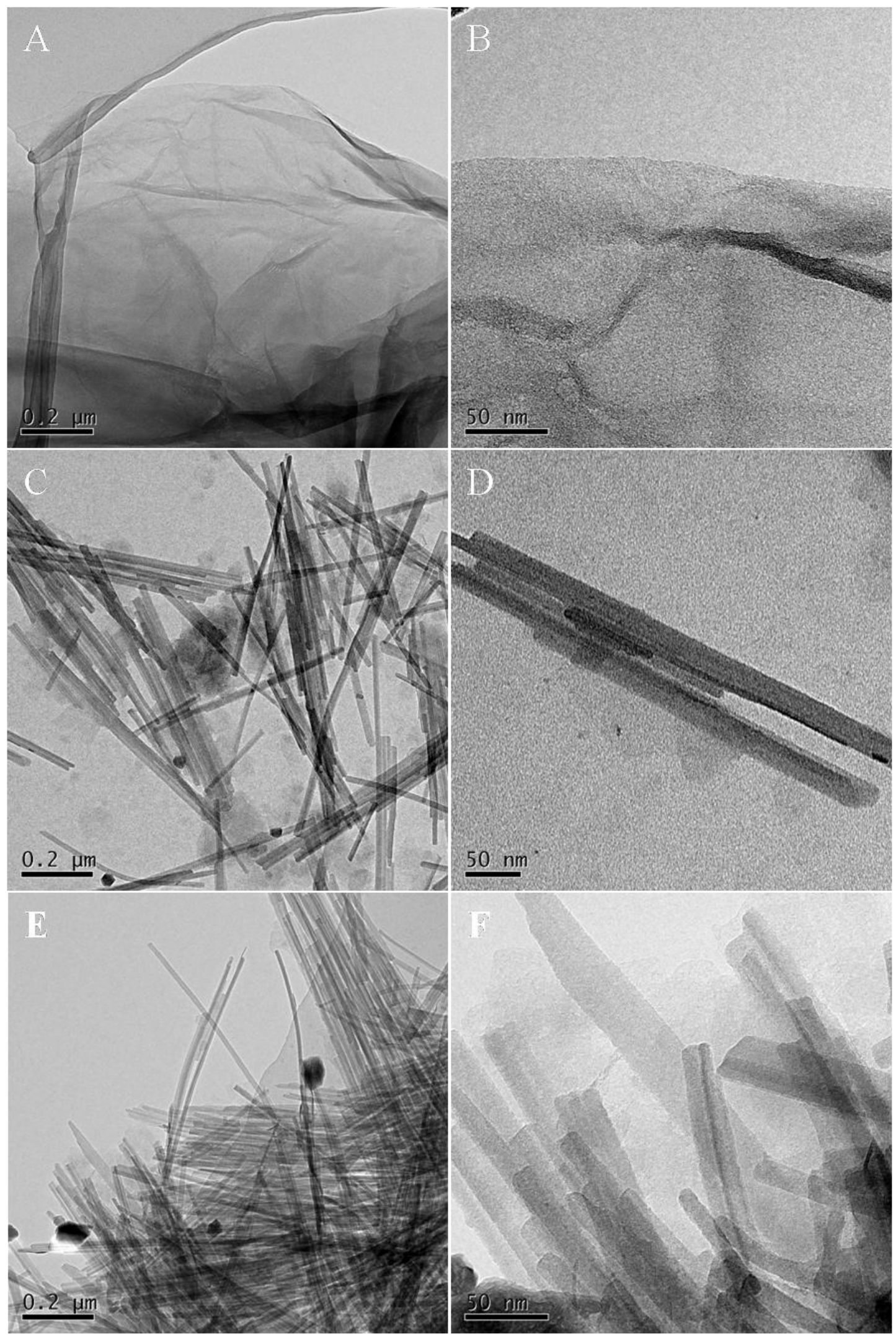

Figure. 3. TEM images of modified electrodes materials $\mathrm{Gr}-\mathrm{COOH}(\mathrm{A}$ and $\mathrm{B}), \mathrm{Pal}(\mathrm{C}$ 
and $\mathrm{D}$ ) and Pal-Gr-COOH (E and F).

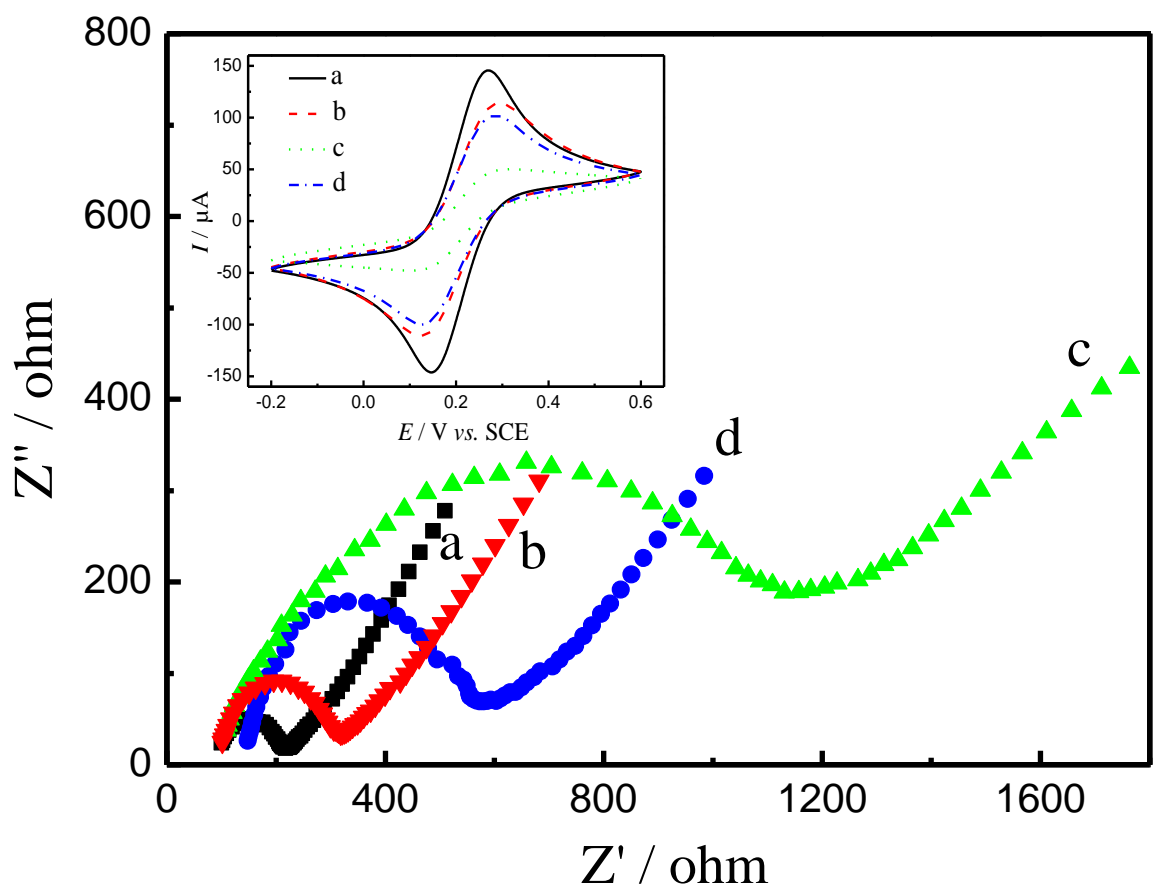

Figure. 4. Nyquest plots of different electrodes: GCE (a), Pal/GCE (b), Gr-COOH/GCE (c), and Pal-Gr-COOH/GCE (d) in $5 \mathrm{mM}\left[\mathrm{Fe}(\mathrm{CN})_{6}\right]^{3-/ 4-}$ containing $0.1 \mathrm{M} \mathrm{KCl}$. Inset: CVs of different electrodes in $5 \mathrm{mM}\left[\mathrm{Fe}(\mathrm{CN})_{6}\right]^{3-/ 4-}$ containing $0.1 \mathrm{M} \mathrm{KCl}$. Scan rate: $50 \mathrm{mV}$ $\mathrm{s}^{-1}$ 

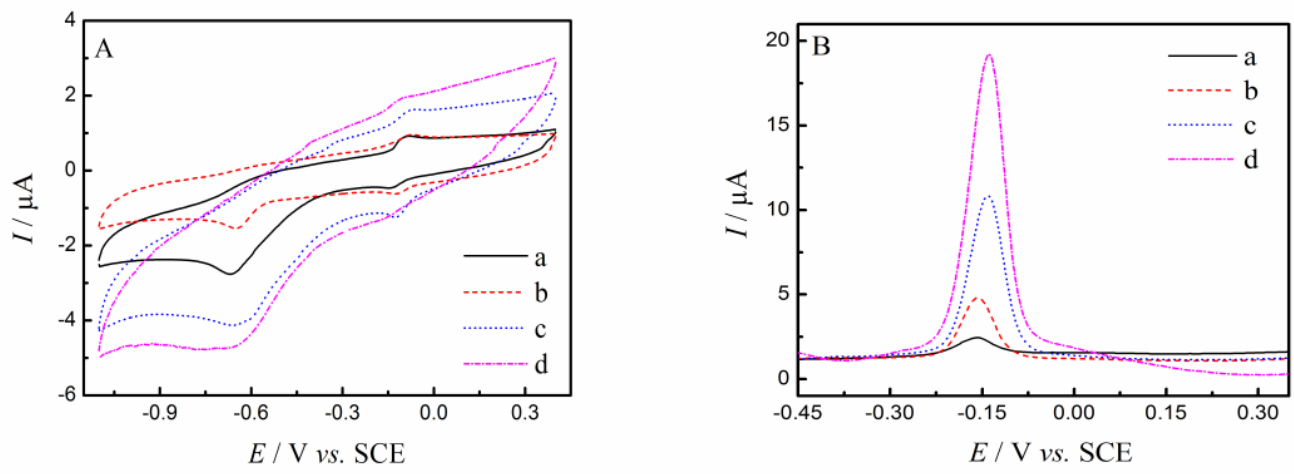

Figure. 5. CVs of $50 \mu \mathrm{M} N A$ at GCE (a), Pal/GCE (b), Gr-COOH/GCE (c) and Pal-Gr-COOH/GCE (d) in $0.1 \mathrm{M}$ phosphate buffered solution ( $\mathrm{pH}$ 7.0) (A). DPASVs of $20 \mu \mathrm{M}$ NA at different electrodes: GCE (a), Pal/GCE (b), Gr-COOH/GCE (c) and Pal-Gr-COOH/GCE (d) in $0.1 \mathrm{M}$ phosphate buffered solution (pH 7.0) (B). 


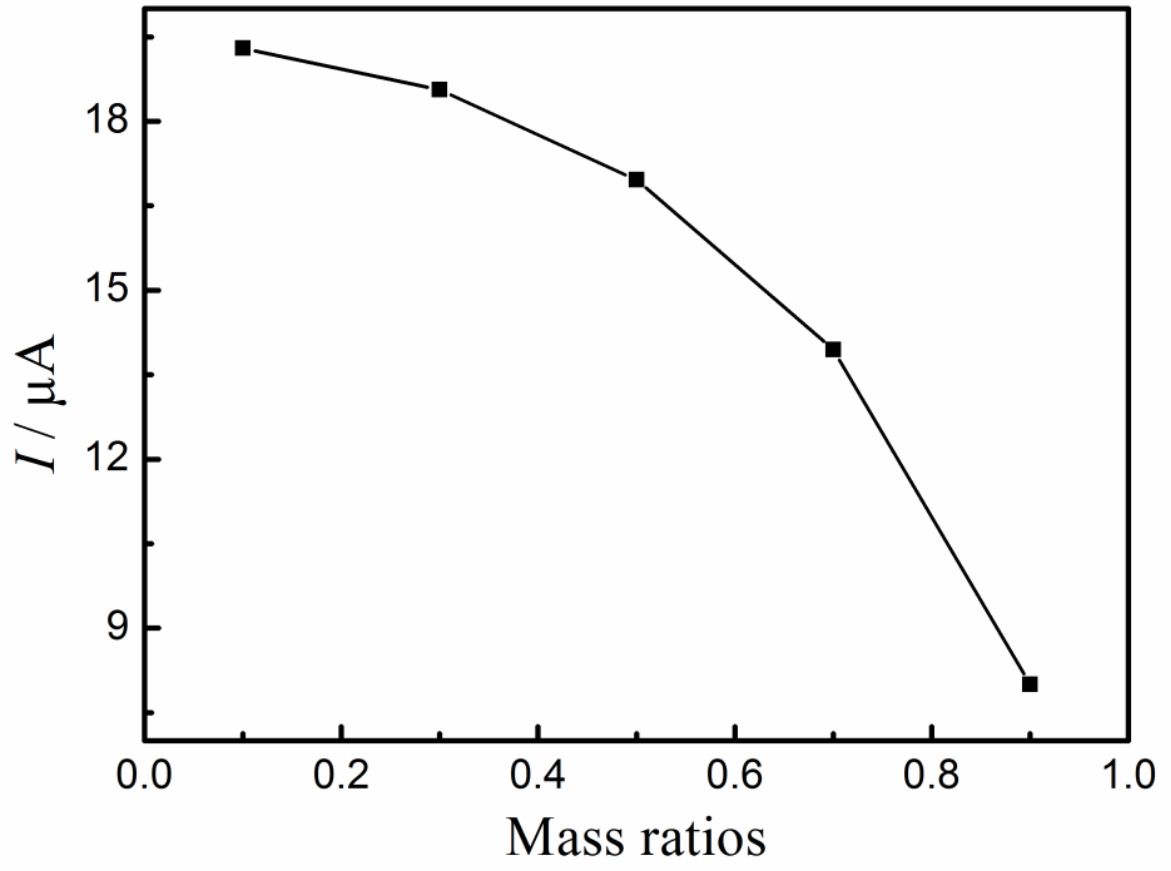

Figure. 6. The effect of mass ratios of $\mathrm{Gr}-\mathrm{COOH}$ to Pal on DPASV current response for NA at Pal-Gr-COOH/GCE. 

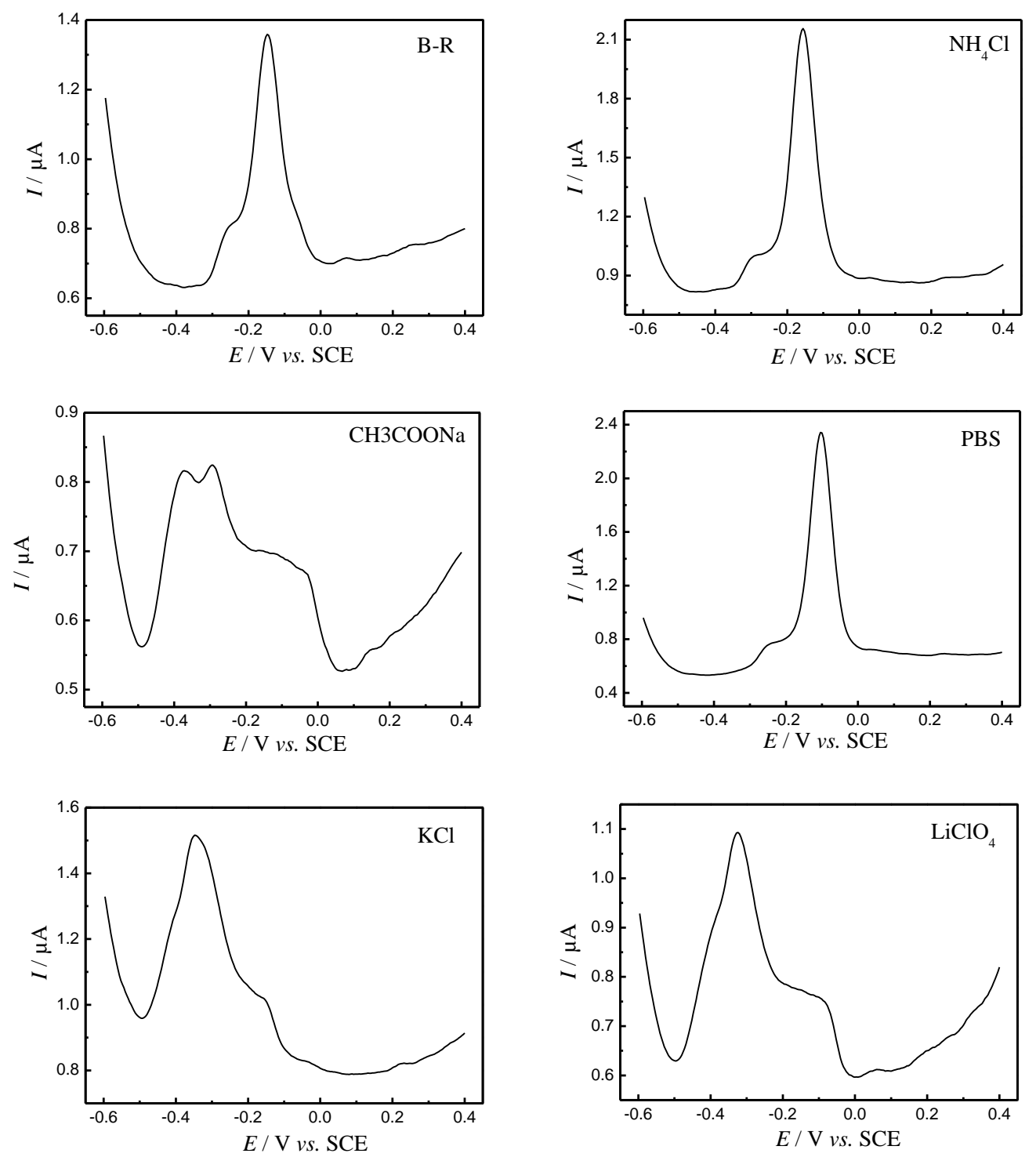

Figure. 7. DPASV of NA in $0.1 \mathrm{M}$ different buffer solutions $(\mathrm{pH} 7.0)$. 


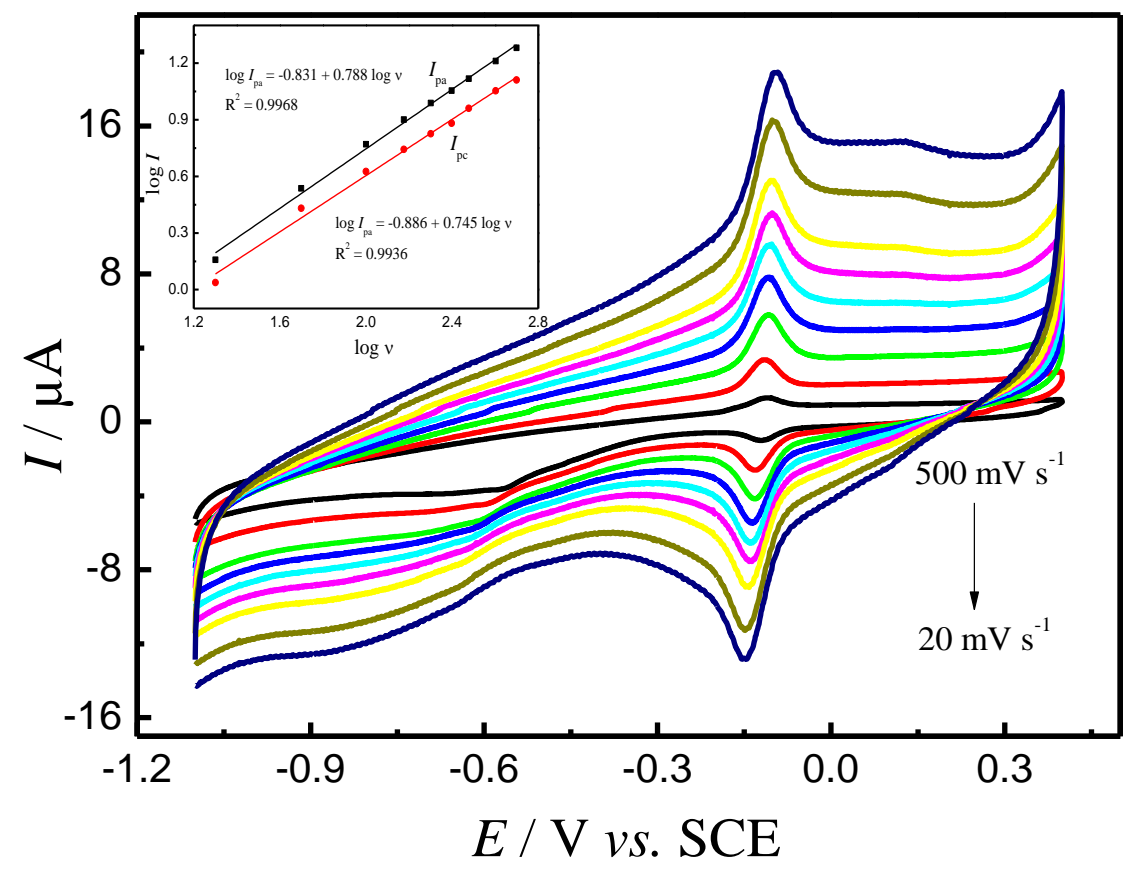

Figure. 8. CVs of $50 \mu \mathrm{M} N A$ at Pal-Gr-COOH/GCE in $0.1 \mathrm{M}$ phosphate buffered solution (pH 7.0) with different scan rates: $20,50,100,150,200,300,400$ and 500 $\mathrm{mV} \mathrm{s}^{-1}$. Inset: the plot of $\log I_{\mathrm{pa}} v s . \log v$. 


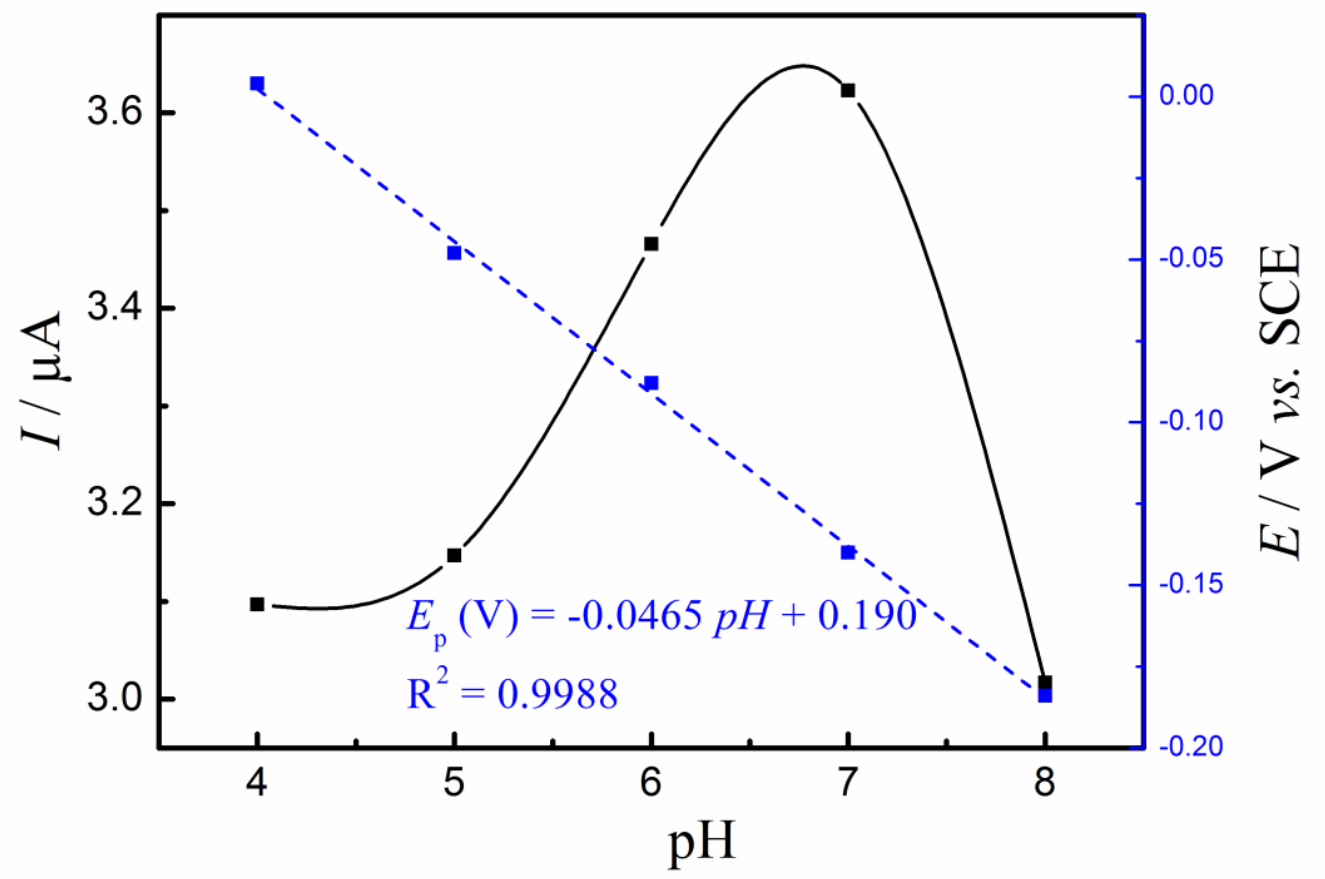

Figure.9. Effect of pH on peak currents and peak potentials. 


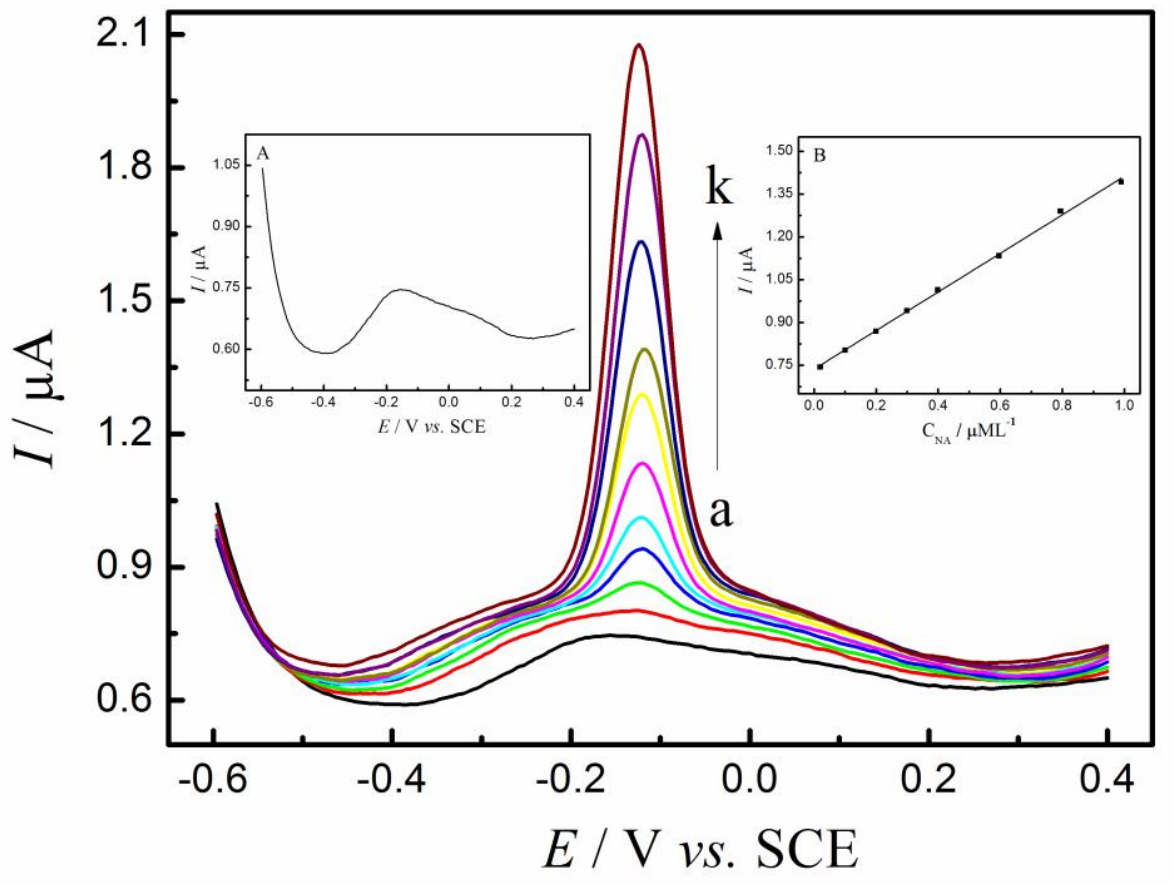

Figure. 10. DPASV for NA detection at Pal-Gr-COOH/GCE. NA concentrations (from a to k): $0.02,0.099,0.199,0.299,0.399,0.596,0.794,0.99,1.96,2.96,4.76 \mu \mathrm{M}$. Inset: DPASV for $0.002 \mu \mathrm{M}$ NA detection at Pal-Gr-COOH/GCE (A) and the calibration range from 0.02 to $0.99 \mu \mathrm{M}(\mathrm{B})$. 


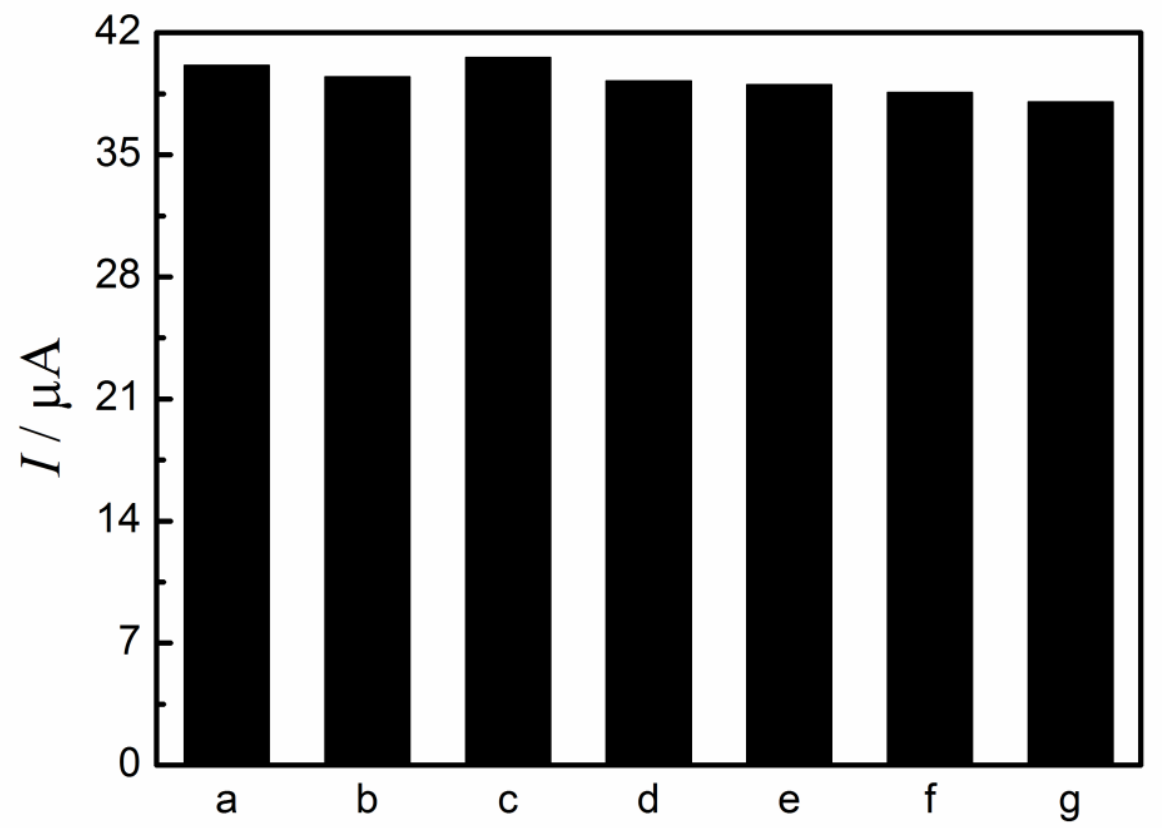

Figure. 11. Influence of coexisting substances on the current response for NA by Pal-Gr-COOH/GCE in $0.1 \mathrm{M}$ phosphate buffered solution (pH 7.0) containing $50 \mu \mathrm{M}$ NA and several interferences $(a, N A ; b, N A+$ glucose; $c, N A+$ nicotinic acid; $d, N A+$ $\mathrm{Na}^{+} ; \mathrm{e}, \mathrm{NA}+\mathrm{Ni}^{2+} ; \mathrm{f}, \mathrm{NA}+\mathrm{K}^{+} ; \mathrm{g}, \mathrm{NA}+$ glucose + nicotinic acid $\left.+\mathrm{Na}^{+}+\mathrm{Ni}^{2+}+\mathrm{K}^{+}\right)$ 


\section{Table 1}

The comparison of electrochemical sensors based on different materials previously used for the determination of NA

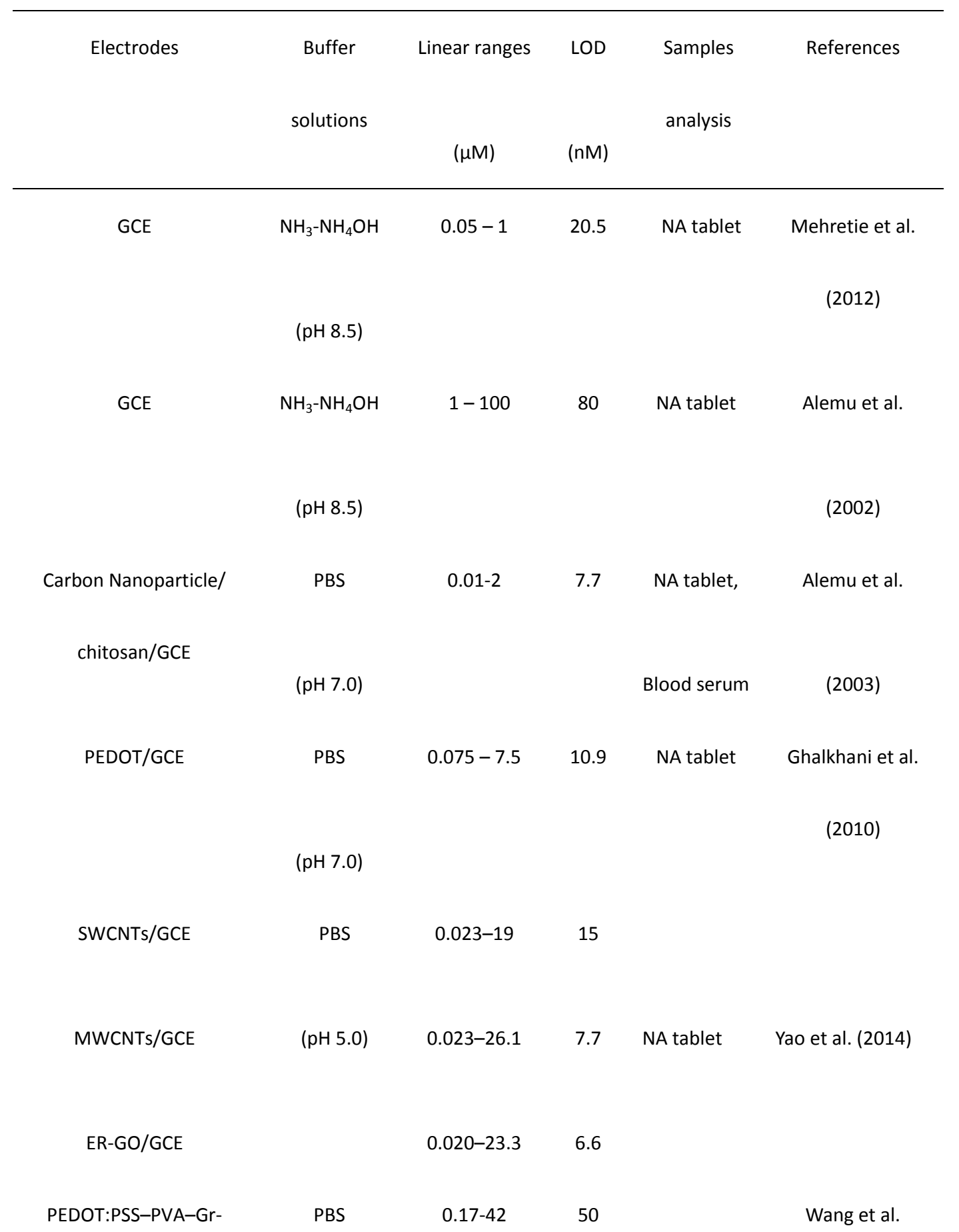


$\mathrm{COOH} / \mathrm{GCE}$

PEG

Pal-Gr-COOH/GCE
(pH 6.5)

(2014)

$\begin{array}{ccccc}\text { BR }(\mathrm{pH} 7.0) & 0.05-10 & 15 & \text { NA tablet } & \text { Dede et al. (2014) } \\ \text { PBS } & 0.02-0.99 & 4.6 & \text { NA tablet } & \text { This work } \\ & & & & \\ & & & \text { Paddy water } & \\ (\mathrm{pH} \mathrm{5.0)} & & & \end{array}$


Table 2

The determination of NA in pharmaceutical tablets and paddy water

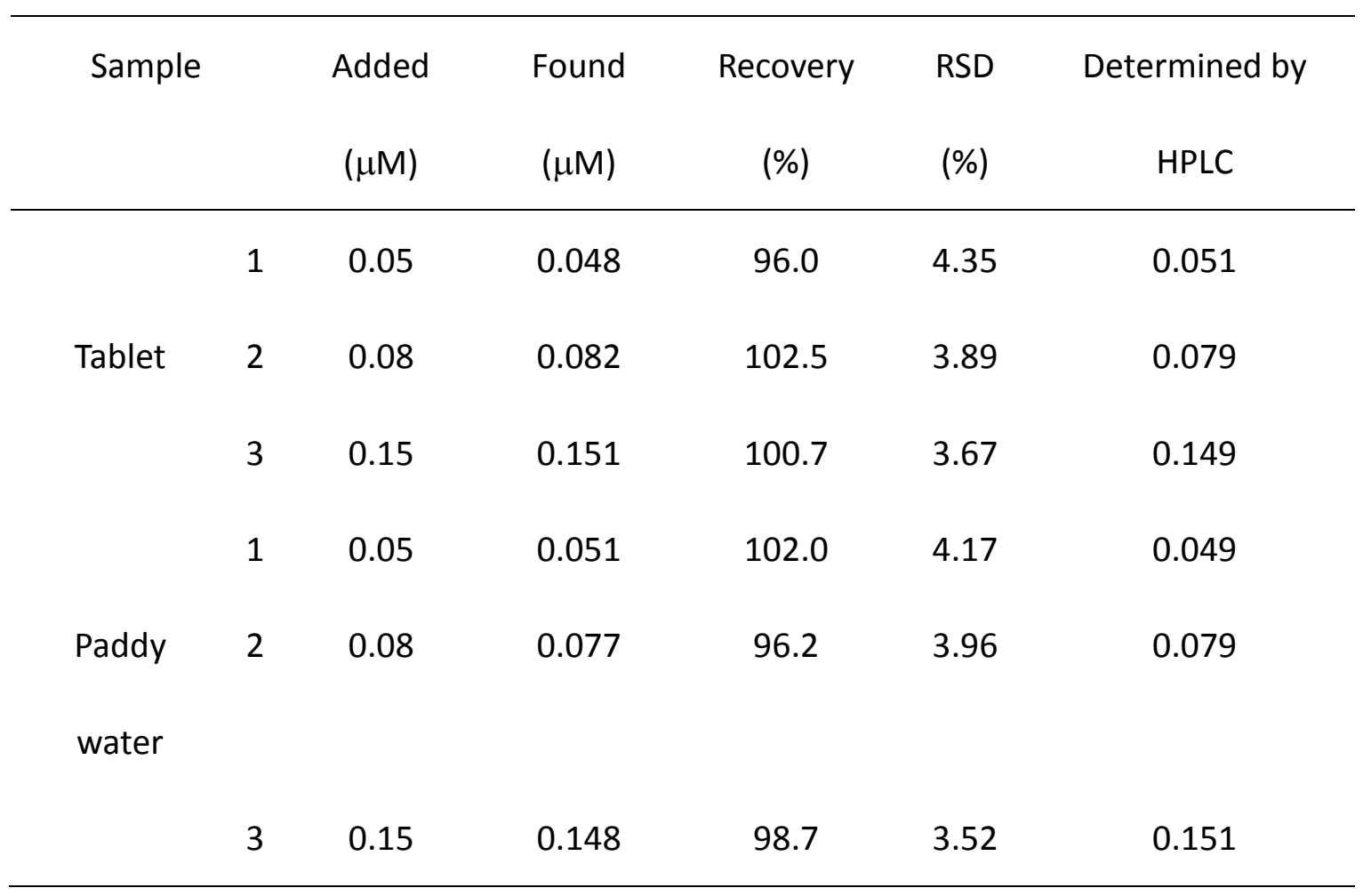




\section{Graphical abstract}

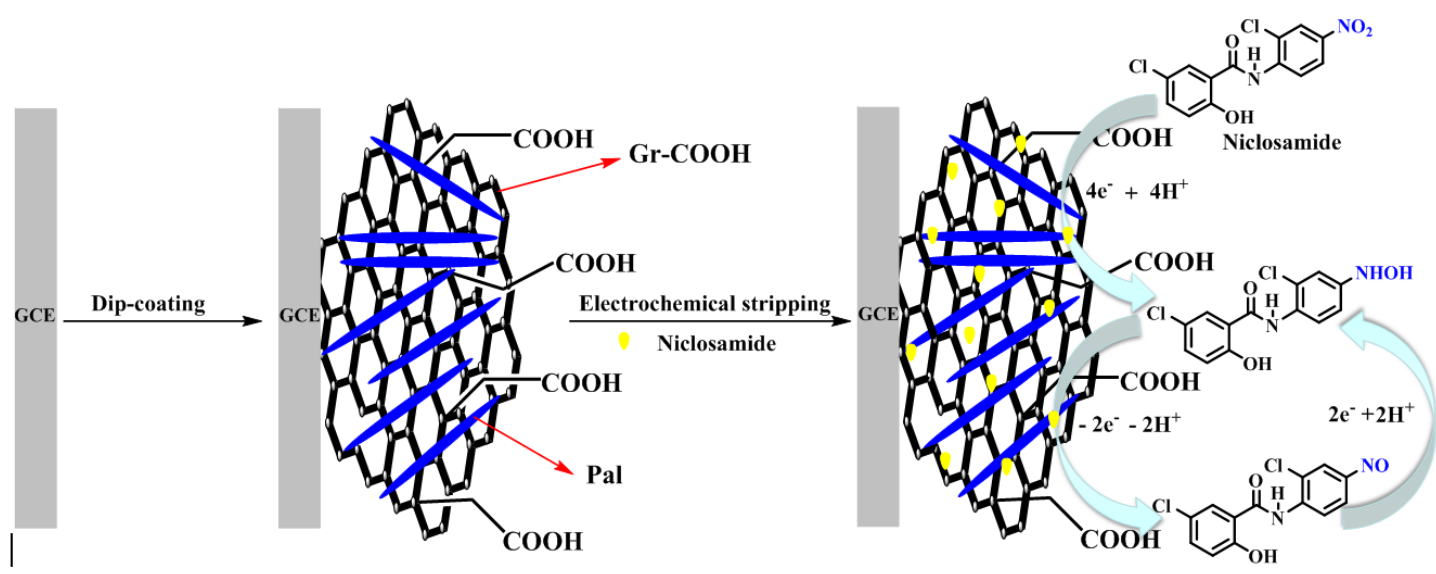

